\title{
Application of Component Technology in Power Simulation Training
}

\author{
Xi-Lan $\mathrm{ZHAO}^{1}$, Geng Wang ${ }^{1}$, Jian-mei Yang ${ }^{1}$ and Feng $\mathrm{GAO}^{2}$ \\ ${ }^{1}$ State Grid Gansu Power Company., Tianshui, China \\ ${ }^{2}$ Beijing Kedong Electric Control System Co. Ltd., Beijing, China
}

\begin{abstract}
With the rapid development of power grid and the implementation of integrated management and control mode, the knowledge, technology and skills of power supply production management personnel have put forward higher requirements, and the establishment of simulation system for the integration of power grid regulation and control is to improve the relevant professionals Quality and skill level of the important means, component-based modeling method can quickly establish the entire power grid of the secondary model, is gradually becoming a new trend in the field of power simulation. The research results of this paper have been successfully applied in the power grid of Gansu Province, with cost-effective, more complete and more realistic simulation, and got good training effect.
\end{abstract}

\section{Introduction}

According to the guiding ideology of national energy development, the State Grid Gansu Electric Power Company fully implement the scientific concept of development, clearly to steadily promote the integration of power grid regulation. In accordance with the requirements of the new management system, power grid regulation and control personnel and substation operation and maintenance personnel to assume the power grid security, stability, economic operation of the responsibility is growing, and with the power grid a large number of new technology and new equipment applications, need to greatly improve the regulation of professionals The quality and skill level in order to ensure its ability to master the operation characteristics of new equipment and control the operation of the power grid to establish the integration of power grid regulation and control system [1] is to improve the quality of relevant professionals and skills level of the important means, The focus of the integrated simulation is the secondary system model of the grid. The secondary system model of the power grid refers to all the plant stations of the whole power grid, and establishes a detailed mechanism model for the secondary control, action time, action logic and action information of the secondary equipment such as its protection, communication, monitoring and control, station $\mathrm{AC}$ and DC, Complete and true reproduction of the secondary system of light plate signal, protection of information, messages and other secondary system of logical behavior and its interactive relationship [2].

Power system simulation A large number of research contents mainly focus on the research of algorithms. However, due to the long-term concern of the algorithm research, making the actual application of the project, there are the following situations: the development of the secondary system model is often carried out in a project, the coupling between the various functional modules is high, making the simulation system design, There are many problems with maintenance and upgrades. Different simulation engineering secondary system model has many functions and applications similar, but because of its lack of standardization, the interface specification is not uniform and other issues, it is difficult to directly use it to reuse. Making the secondary system model of the flexibility and reusability of the key advantages of difficult to play, engineering development most of the time are used in the reconstruction of these secondary models, which makes the power training simulation system has become a costly system engineering, In the regulation of integrated management model this problem is more prominent. Therefore, it is an urgent requirement and key to promote the development of power simulation technology by encapsulating the secondary system model of the power grid into a simulation component with standardized interface, reusable, versatile, scalable and low coupling.

\section{Development of Power Simulation Modeling Technology}

Before the 1990s, the realization of the electric power training simulation system basically adopted the modular modeling method. The modular modeling method adopts the process-oriented design. The simulation system can only be used to describe the model by the process function. Scale simulation of complex systems. With the development of modular design, such as attributes, methods, examples and other concepts, the mid-90s gave 
birth to the development of object-oriented modeling technology to promote the power training simulation system to object-oriented modeling direction. Objectoriented simulation technology breaks through the shackles of traditional concepts, makes the modeling process close to people's normal logical thinking mode. The established model has inherent extensibility and reusability, which is conducive to the establishment of graphical modeling and simulation environment, Thus providing support for simulation analysis of large complex systems. However, object-oriented design methods are also flawed, the degree of coupling between simulation applications is high, scalability and reusability are not strong, the lack of object semantic information, the model is not easy to support multi-application, is not conducive to the development of joint simulation system. As a result of object-oriented modeling methods, component-based software modeling methods are gradually becoming a new trend in power simulation. Compared with the traditional power simulation system modeling technology, the componentized power simulation system modeling technology embodies the idea of software reuse, improves the reusable and extensible features of the simulation system, and makes the simulation system easy to upgrade and maintain, Thus improving the development efficiency.

\section{Application of Component Modeling Technology}

Process-oriented programming reuse functions, objectoriented programming reuse classes, and component programming reuse specific functional integrity modules. The basic idea of component software technology is to build a software framework that divides large and complex software applications into a series of software unit components that can be implemented, easy to develop, understand and adjust. Each component is functionally defined, individually designed, separately encoded, and each component provides some standard and simple application interfaces that allow the user to set and adjust parameters and attributes. Users can organically combine multiple components from different sources to quickly form a complex application that meets the actual needs. Therefore, component-based software system solutions, the development of high efficiency, low investment, low maintenance costs, reuse ability, software upgrades simple.

The software framework is an important way to achieve large granularity reuse. Is a reusable "semifinished" software for a field (including business areas such as ERP, and computing, such as a GUI) that implements the common parts of the field and provides a series of well-defined variable points To ensure flexibility and scalability.

In order to solve the above problem, it is proposed that the secondary model of the power grid is difficult to reuse, manage the confusion and build difficult. This paper draws up the idea of "software reuse", and proposes a construction scheme of power system secondary system simulation modeling platform based on component technology. We first set up the power simulation software framework. Second, the need for the secondary model of the power grid to be component-based design, packaging; again, for the simulation components to establish a standardized external data interface; Finally, the establishment of user-friendly graphical modeling tools to complete the simulation component management and simulation system structures Function, so as to quickly achieve the entire power grid secondary system modeling. The following is an example of how to establish a modularization model for the secondary system of the grid by taking the RCS-931 device as a line protection:

(1) to establish a suitable software for the integration of network control simulation application framework

Compared with the ordinary components, the framework of a larger particle size, reflecting the common domain. The integrated simulation software framework includes at least the following components: the relationship between the components and the interaction mechanism, a series of variable points and variable point behavior adjustment mechanism.

Component replacement is achieved through a bus mechanism in the software framework, adding the already identifiable components with relatively independent functions to the system via the bus. Developers through the variable point of the behavior adjustment mechanism, the simulation component bound to the software frame of the variable point, resulting in the final realization of power grid integrated simulation system, this process is called the software framework of the instantiation process. Through the use of software framework, developers can focus on the specific part of the system, which greatly improved the integration of simulation system development efficiency and quality.

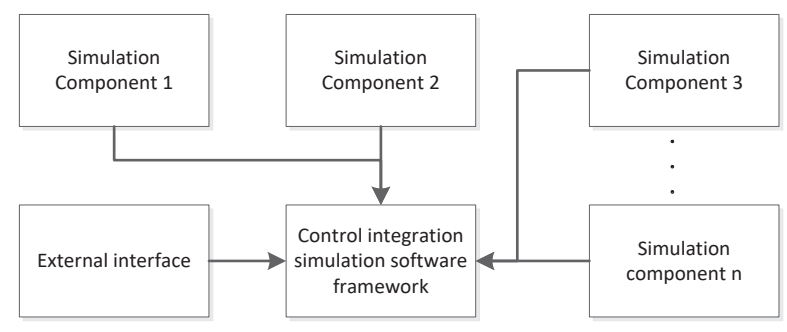

Figure 1.control integration simulation software structure diagram

Software framework includes data management, event management, simulation component management, simulation interface management.

Data management: Due to the real-time requirements of the simulation system, a large amount of data exchange is required during the simulation run. Our software framework provides the use of data bus to achieve rapid exchange of high-volume data, providing data distribution management services.

Event Management: You can broadcast events, or you can dynamically update the execution list by simulating the sequence of events triggered by each component.

Simulation component management: Provides component registration, configuration component parameters, component initialization, component addition, delete and other functions. Provide service management, 
time management and other services for each simulation component on the platform.

Simulation interface management: for the system simulation process to provide interface operations, including human-machine interface start, operation, pause, recovery, fault and other external trigger events.

(2) The line protection RCS-931 unit is packaged in a package

1) package part model. The components of the RCS931 unit are divided into signals, platens, switch handles, buttons and other types. All components are encapsulated in the part model file according to their type, as shown in Table 1:

Table 1. Example of RCS-931 operating part model

\begin{tabular}{|l|l|l|}
\hline Control type & Name & Status \\
\hline$<$ Signal $>$ & Protection action & OFF \\
\hline$<$ Signal $>$ & Reclosing action & OFF \\
\hline$<$ Plate $>$ & DC power air switch & ON \\
\hline$<$ Plate $>$ & AC power air switch & ON \\
\hline$<$ Plate $>$ & Main protection & ON \\
\hline$<$ Button $>$ & Signal return & OFF \\
\hline$<$ Switch handle $>$ & Reclosing method & Single-phase \\
\hline
\end{tabular}

2)encapsulation logic model. Line protection RCS931 device is composed of multiple protection function plug-in, respectively, the implementation of different protection functions, each protection plug-in internal logic is defined as an expression, all the logical expression saved to the internal logic model file, Constitute the internal logic model, as shown in Table 2.

Table 2. RCS-931 internal logic model example

\begin{tabular}{|l|l|l|}
\hline $\begin{array}{l}\text { Function } \\
\text { protection plugin }\end{array}$ & Action conditions & $\begin{array}{l}\text { Action } \\
\text { information }\end{array}$ \\
\hline $\begin{array}{l}<\text { Current } \\
\text { differential } \\
\text { protection }>\end{array}$ & $\begin{array}{l}<\text { Differential current } \\
=1 \& \& \text { Plates: Main } \\
\text { protection=ON }>\end{array}$ & $\begin{array}{l}<\text { Signal: } \\
\text { protection } \\
\text { action ON }>\end{array}$ \\
\hline $\begin{array}{l}<\text { Split Differential } \\
\text { protection }>\end{array}$ & $\begin{array}{l}<\text { Split differential } \\
\text { current }=1 \& \& \text { Main } \\
\text { protection=ON }>\end{array}$ & $\begin{array}{l}<\text { Signal: } \\
\text { protection } \\
\text { action ON }>\end{array}$ \\
\hline$<$ Reclose $>$ & $\begin{array}{l}<\text { Breaker trip }=1 \\
\& \& \text { switch handle: } \\
\end{array}$ & $\begin{array}{l}<\text { Signal: } \\
\text { reclosing } \\
\text { action ON }>\end{array}$ \\
& Single-phase $>$ & \\
\hline
\end{tabular}

The operating conditions in the table $<$ Differential current $=1 \& \&$ Plates: Main protection $=\mathrm{ON}>$ Meaning of the logical expression: the line is differential and the master protection plate is in the input state condition, the current differential protection will act. Action information < signal: protection action : $\mathrm{ON}>$ Meaning of logical expression: current differential protection action to send protection action information.

(3) establish a standardized data interface for the RCS-931 component

The component interface adopts the XML design criterion, the component model is separated from the component interface, and the component model and the component interface hierarchy can be expanded independently. XML-based interface is simple, easy to expand, easy to achieve standardization of interface data, as shown in Table 3.

Table 3. RCS-931 component interface example

\begin{tabular}{|c|c|}
\hline Data type & Interface data \\
\hline $\begin{array}{l}\text { Grid fault data } \\
\text { ( Tianshui station } \\
\text { TianPu line A } 20 \% \text { of } \\
\text { the ground at the } \\
\text { permanent fault, } \\
\text { grounding } 100 \% \text { ) }\end{array}$ & $\begin{array}{l}<\text { Station name }>\text { Tianshui }</ \text { station } \\
\text { name }> \\
<\text { Line name }>\text { Tianpu }</ \text { line name }> \\
<\text { Fault type }>\text { line fault }<\text { fault type }> \\
<\text { Fault name }>\text { single phase ground }</ \\
\text { fault name }> \\
<\text { Fault difference }>\text { A phase }</ \text { fault } \\
\text { difference }> \\
<\text { Fault location }>20 \%<\text { fault } \\
\text { location }> \\
<\text { Degree of grounding }>100 \%<< \\
\text { degree of grounding }> \\
<\text { Duration }>9999 \mathrm{~s}</ \text { duration }>\end{array}$ \\
\hline $\begin{array}{l}\text { Operating } \\
\text { displacement } \\
\text { data(Exit the } \\
\text { Tianshui Station } \\
\text { TianPu Line RCS- } \\
\text { 931 Main Protection } \\
\text { Plate) }\end{array}$ & $\begin{array}{l}<\text { Station name }>\text { Tianshui }</ \text { station } \\
\text { name }> \\
<\text { Line name }>\text { Tempe line }</ \text { line } \\
\text { name }> \\
<\text { Device name }>\text { RCS }-931</ \text { device } \\
\text { name }> \\
<\text { Device number }>1</ \text { device } \\
\text { number }> \\
<\text { Control type }>\text { plate }</ \text { control type }> \\
<\text { Control name }>\text { main protection }</ \\
\text { control name }> \\
<\text { Target status }>\text { OFF }</ \text { target status }>\end{array}$ \\
\hline
\end{tabular}

(4) through the graphical component modeling tools to complete the above components of the management and simulation system to build the work

Component library provides users with a wealth of simulation components, and the establishment of a unified simulation component information description, in order to better and faster to build a power simulation system provides a strong support. Component library structure shown in Tabel 4:

Table 4. Component library structure

\begin{tabular}{|l|l|l|}
\hline $\begin{array}{l}\text { Protection } \\
\text { name }\end{array}$ & $\begin{array}{l}\text { Protection } \\
\text { type }\end{array}$ & Manufacturer \\
\hline PRS-723A & Breaker & $\begin{array}{l}\text { NARI TECHNOLOGY } \\
\text { CO., LTD }\end{array}$ \\
\hline PRS-723AH & Breaker & $\begin{array}{l}\text { NARI TECHNOLOGY } \\
\text { CO., LTD }\end{array}$ \\
\hline PRS-723CF & Breaker & $\begin{array}{l}\text { NARI TECHNOLOGY } \\
\text { CO., LTD }\end{array}$ \\
\hline PSL-631A & Breaker & $\begin{array}{l}\text { Guodian Nanjing } \\
\text { Automation Co.,LTD }\end{array}$ \\
\hline PSL-631C & Breaker & $\begin{array}{l}\text { Guodian Nanjing } \\
\text { Automation Co.,LTD }\end{array}$ \\
\hline PSL-631U & Breaker & $\begin{array}{l}\text { Guodian Nanjing } \\
\text { Automation Co.,LTD }\end{array}$ \\
\hline
\end{tabular}

Graphical component modeling tool is a component management, component assembly interface, the role is to ensure that users in accordance with the correct method of implementation, allowing users to more simply complete the simulation system to build the work. As shown in Tabel 5 below, users only need to select the component model from the device component library to 
complete the construction of the secondary model of the grid.

Table 5. Graphical component modeling platform

\begin{tabular}{|l|l|l|l|l|}
\hline Station & $\begin{array}{l}\text { Devic } \\
\text { e type }\end{array}$ & Device name & $\begin{array}{l}\text { Protecti } \\
\text { on name }\end{array}$ & $\begin{array}{l}\text { Protection } \\
\text { number }\end{array}$ \\
\hline Tianshui & Bus & $500 \mathrm{kV}$ bus I & BP-2B & 1 \\
\hline Tianshui & Bus & $500 \mathrm{kV}$ bus I & BP-2B & 2 \\
\hline Tianshui & Bus & $500 \mathrm{kV}$ bus II & BP-2B & 1 \\
\hline Tianshui & Bus & $500 \mathrm{kV}$ bus II & BP-2B & 2 \\
\hline
\end{tabular}

\section{Application}

The research results have been successfully applied to the State Grid Gansu Electric Power Company, and the relevant production personnel have been trained in the normal operation skills, abnormal and accident handling skills of the grid, and achieved good results. System structure shown in Figure 2:

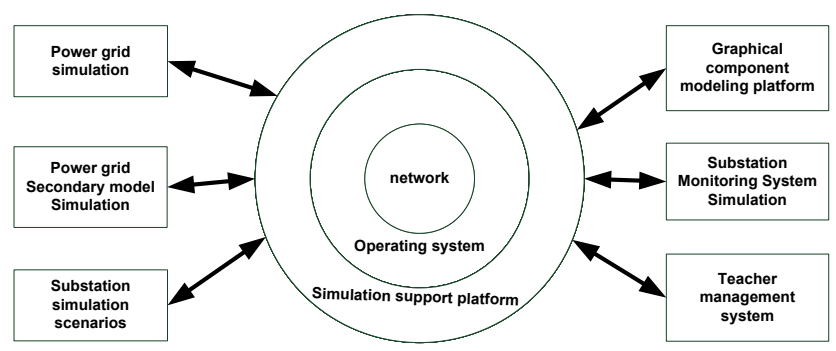

Figure 2. Power simulation system structure diagram

Power grid simulation, power network secondary model simulation, substation three-dimensional scene simulation, substation monitoring system simulation, teacher management system and graphical component modeling platform constitute the entire software system, the module through the simulation run support platform [3] to achieve the simulation process time Synchronization, information interaction and coordination control, Figure 3 gives the overall structure of the software system.

(1) grid simulation to achieve the power grid transient, medium and long-term process of integrated simulation [2], power grid simulation of a device active, reactive, current, voltage and other remote measurement and circuit breaker and the state of the remote signal sent to the Other emulation applications, and receive operational events sent by other emulation applications and emulate

(2) The simulation of the secondary simulation module of the power grid is based on the simulation of the power grid. The logic behavior of the secondary control system, the measurement system, the error prevention system, the AC system, the DC system, the relay protection and the automatic device are simulated. Sub-equipment and secondary circuit simulation results sent to the grid simulation, substation scene and substation monitoring simulation module, and receive the three modules of the operating instructions.

(3) substation monitoring system simulation: simulation of substation monitoring system functions, man-machine interface and operation process, [4] have a detailed discussion.

(4) substation scene simulation is the use of OPENGL [5] [6] three-dimensional engine development. It uses the model editor, the scene editor to establish the substation equipment and scene model, to carry out the scene roaming, virtual operation and other training, the image of the reproduction of the entire production process of substation.

(5) graphical component modeling platform to complete the management of the secondary network simulation components and power grid secondary simulation system to build the work.

(6) The teacher management module is responsible for the whole process of management, monitoring, control, training before the preparation, training, analysis, monitoring, control and management, as well as posttraining evaluation and other functions and man-machine composition.

\section{Summary}

With the rapid development of power grid, processoriented or object-oriented modeling method has been unable to meet such a large and complex power grid secondary system. This paper draws on the idea of software reuse in software engineering, and proposes to build a power simulation modeling platform based on the component software framework. First, the establishment of a modular software framework. Secondly, the framework of the core components of the standardized thinking of the design package logic model. Again, establish a standardized data interface for the component. Finally, the establishment of graphical modeling tools to complete the management of simulation components, modeling and simulation system to build and other functions. To help users quickly configure the simulation system to achieve the reproduction of the simulation process, thereby enhancing simulation modeling efficiency.the system has been successfully applied to the State Grid Gansu Electric Power Company, and achieved good results.

\section{References}

1. Jiang Yefeng, Wei Wenhui, Gao Feng, et a1. "Design and implementation of integrated simulation and simulation application based on SG - OSS". China Electric Power, vol.47, pp. 80-85 (2014).

2. Huang Wentao, Wei Wenhui, Wu Jihao. "Multi level joint simulation system based on digital physics hybrid simulation technology of substation". Power Grid Technology, vol. 36, pp. 95-98 (2008).

3. Yang Xuanhuai, Lin Changnian, Wang Guoping, et a1. "A comprehensive simulation platform of power system based on high - level architecture". Power Grid Technology, vol. 33, pp. 98-103 (2009).

4. Hai Xiaotao, Lin Wei, Gao Feng, Ge Xianjun. "Northwest $750 \mathrm{kV}$ AC and DC hybrid power network integrated simulation system". Power Grid Technology, vol. 36, pp. 254-259 (2012). 
5. Li Weiqing, Wu Huizhong, Lin Changian. "Research and Implementation of Virtual Environment for Substation Simulation System". Journal of System Simulation, vol. 18 pp. 123-126 (2006).
6. Hou Jun, Li Weiqing, Lin Changian. "Research on Key Technology of Three - dimensional Interactive Scene Simulation in Substation". Power Grid Technology, vol. 29 pp. 70-75 (2005). 